wheeze, or breathlessness?'). ${ }^{3}$

In the UK, there are a total of over 800000 (prevalence 1.5\%) people on general practice COPD registers (Quality and Outcomes Framework data). ${ }^{4}$ However, cross-sectional studies and extrapolation of data indicate that the actual prevalence should be nearer to $4 \%$. More than half of the people with COPD are currently not identified. ${ }^{5,6}$ The main conclusion is that symptoms are unreliable and the availability of spirometry for all those at risk remains the only way to identify those missing millions.

Until NICE comes fully into line within criteria for diagnosis and is prepared to ignore unreliable subjective symptom scoring, then these figures are unlikely to improve and a state of confusion and uncertainty will remain.

\section{Gary Parkes,}

GP/Researcher, The Limes Surgery,

Hoddesdon, Herts.

E-mail:parkesko@hotmail.co.uk

\section{REFERENCES}

1. O’Reilly J, Jones MM, Parnham J, et al. Management of stable chronic obstructive pulmonary disease in primary and secondary care: summary of updated NICE guidance. $B M J$ 2010; 340: c3134.

2. Agusti A, Calverley PM, Celli B, et al. Characterisation of COPD heterogeneity in the ECLIPSE cohort. Respir Res 2010; 11: 122.

3. Lu M, Yao WZ, Zhong NS, et al. Asymptomatic patients of chronic obstructive pulmonary disease in China. Chin Med J (Engl) 2010; 123(12): 1494-1499.

4. NHS. Quality and Outcomes Framework (QOF) for April 2008 - March 2009, England numbers on QOF disease registers and raw prevalence rates, England. http://www.ic.nhs.uk/ (accessed 15 Feb 2011).

5. Van Schayck CP, Loozen JMC, Wagena E, et al. Detecting patients at a high risk of developing chronic obstructive pulmonary disease in general practice: cross sectional case finding study. BMJ 2002; 324(7350): 1370.

6. Shahab L, Jarvis MJ, Britton J, West R. Prevalence, diagnosis and relation to tobacco dependence of chronic obstructive pulmonary disease in a nationally representative population sample. Thorax 2006; 61(12): 1043-1047.

\section{Screening for atrial fibrillation}

I was reading with interest the article of Lewis et al about the use of a new gadget for the detection of atrial fibrillation in general practice. ${ }^{1}$ The diagnosis of atrial fibrillation is very important, but do we need to invest in further instruments to screen for atrial fibrillation?

I think a cardiac auscultation should be part of a consultation, especially in the high older risk group. I diagnosed people in their 50 s with atrial fibrillation who consulted me for their phimosis or for losing weight. Initially amused about the cardiac auscultation they were very thankful when I explained that their heart rhythm, if not treated, could cause serious problems in the future, for example, stroke.

Despite having had several consultations as a patient with several GPs in my life, no one checked my blood pressure or did auscultate my heart as yet (despite me being in my 50s). We have to come back to the physical examination that is more costeffective and a quick screening tool when it is combined with prior adequate training and clinical reasoning. Not only are rhythm disturbances important, but structural heart disease can be asymptomatic, for example, in aortic regurgitation, despite being a serious cardiac abnormality.

Normal physical examination can exclude valvular regurgitation in asymptomatic patients, and no echocardiogram is necessary. If GP colleagues feel rusty regarding cardiac auscultation there are very good websites available to update oneself with murmurs and rhythms, or one could sit in with a cardiology colleague. One good heart sound tutorial, that is available free on the internet is 'Blaufuss Multimedia - Heart Sounds and Cardiac Arrhythmias'.2

I hope that we are all listening to the patient more. This is not meant only for the soul, but applies to the body as well.

\section{Bernard Klemenz,}

Northern Road Surgery, 56 Northern Road, Cosham, P06 3DS.

E-mail: bernard@doctors.org.uk

\section{REFERENCES}

1. Lewis M, Parker D, Weston C, Bowes M. Screening for atrial fibrillation; sensitivity and specificity of a new methodology. Br J Gen Pract 2011; 61(582): 38-39.

2. Blaufuss A. Cardiac examinations/heart sounds. http://www.blaufuss.org/ (accessed 7 Mar 2011).

DOI: 10.3399/bjgp11X567243

\section{Integrated medicine}

Brien et al interviewed 35 patients who were using complementary and alternative medicine (CAM) in parallel with orthodox medicine. ${ }^{1}$ They state that 'there has been no direct research into how individuals use CAM and OM (orthodox medicine) in relation to each other ...'. This may not be entirely correct. In 1997 , we published a survey of 3384 arthritis sufferers and analysed the data of 496 patients using both orthodox medicine and CAM. ${ }^{2}$ Our results suggested that orthodox medicine was generally perceived as more effective but the therapeutic encounters with providers of CAM were perceived as more satisfying. For instance, $64 \%$ of patients felt that CAM clinicians spent enough time with them, while, for orthodox doctors, the figure was only $45 \%$. Brien at al ${ }^{1}$ show that, predictably, patients use CAM and orthodox medicine in 'different ways'. I suggest that our 1997 findings $^{2}$ go some way in explaining why.

\section{Edzard Ernst,}

Peninsula Medical School, Exeter.

E-mail: eernst@pms.ac.uk

\section{REFERENCES}

1. Brien SB, Bishop FL, Riggs K, et al. Integrated medicine in the management of chronic illness: a qualitative study. Br J Gen Pract 2010; DOI: 10.3399/bjgp11X556254

2. Resch KL, Hill S, Ernst E. Use of complementary therapies by individuals with 'arthritis'. Clin Rheumatol 1997; 16(4): 391-395.

\title{
Medical migrants
}

The article by Simpson and Esmail in the 
March issue of the BJGP gives only two solutions to the provision of out-of-hours care, asking doctors to take it on as a duty or to pay more for it. Perhaps one reason why some of us do not do outof-hours care is because the in-hours pay means we do not have to. Our colleagues on the continent earn far less. For many, out-of-hours pay at $£ 45$ would seem a very generous wage. Perhaps other avenues, like making it essential for revalidation, as in Holland, may make this an essential part of patient care better resourced by local doctors. Or should we hand in the towel and accept that this service cannot be provided in the face of 24-hour choice and let the 999 services take the strain (and cash)?

\section{John Sharvill,}

Balmoral Surgery, Deal, Kent.

E-mail: john.sharvill@NHS.NET

\section{REFERENCE}

1. Simpson JM, Esmail A. The UK's dysfunctional relationship with medical migrants: the Daniel Ubani case and reform of out-of-hours services. Br J Gen Pract 2011; 61(584): 208-211.

DOI: 10.3399/bjgp11X567261

\section{Revalidation}

I have just been reading Greenhalgh and Wong's very sensible article about revalidation. ${ }^{1}$ I am just about to do my first appraisal. I have looked at all the online portfolios I can find, including the NHS Appraisal Toolkit, the RCGP ePortfolio, and the new GPonline portfolio.

My problem is that they are all good for providing 'evidence', but that none of them is actually a good learning tool. I want a tool that allows me to store relevant clinical information and retrieve it again easily. A traditional computer file system is perfect for me, allowing me to subdivide into as many categories as I like, thus easily facilitating information retrieval. An ideal portfolio would allow us to prove that we've 'ticked the boxes' and would support learning by allowing easy information retrieval and by allowing the user to manipulate the system to their learning style. A system along the lines of 'Google Docs' or 'Evernote' would surely not be too hard to create. Revalidation should be about 'continuous professional development', not 'box ticking' and the eportfolios should reflect this.

\section{Louise Cockram,}

94 Queens Road, Gosport,

Hampshire, PO12 1LH.

E-mail: louisecockram@doctors.org.uk

\section{REFERENCE}

1. Greenhalgh T, Wong G. Revalidation: a critical perspective. Br J Gen Pract 2011; 61(584): 166-168.

DOI: 10.3399/bjgp11X567270

\section{Correction}

In the Back Pages article: Lasserson M. How do we learn? Br J Gen Pract 2011; 61(584): 232-233, the first paragraph: 'It was Harry Secombe who ... before I entered general practice' was included in error. The article should start with the section 'How I learnt to refer'. This has been corrected in the online version.

DOI: 10.3399/bjgp11X567289 